\title{
Erratum zu: Förderung von umweltfreundlichen Verkehrsmitteln durch Gamification und Serious Games
}

\author{
Andreas Gilbert M.Eng., Prof. Dr.-Ing. Petra K. Schäfer \\ (Frankfurt University of Applied Sciences), \\ Thomas Tregel M.Sc., PD Dr.-Ing. Stefan Göbel \\ (Technische Universität Darmstadt)
}

\section{Erratum zu: \\ Kapitel „Förderung von umweltfreundlichen Verkehrsmitteln durch Gamification und Serious Games" in: H. Proff (Hrsg.), Neue Dimensionen der Mobilität, https://doi.org/10.1007/978-3-658-29746-6_58}

„Der Name des Erstautors im Beitrag „Förderung von umweltfreundlcihen Verkehrsmitteln durch Gamification und Serious Games“ lautet Andreas Gilbert.“ 